\title{
Ecosystem Valuation: Changing Discourse in a Time of Climate Change
}

Abstract: Alternative ecosystem valuation methodology can inform policy choices to better reflect local needs, improve living standards and facilitate more effective climate change adaptation strategies. In the context of the South Pacific Island Countries and their reliance on marine resources, this paper outlines the urgent need for exploring alternative ecosystem valuation methodology. The objective behind alternative ecosystem valuation methodology is to enable a more comprehensive identification and elicitation of the various types of ecosystem values. This paper demonstrates how the commonly adopted monetary approach to conducting ecosystem valuation impedes the exploration of climate change adaptation strategies based on non-monetary aspects. These include value-indicators such as time, labour, geographical distance and collective community efforts along with social value, e.g. community incentives to protect and sustain local ecosystems. The paper compares and contrasts various combinations of ecosystem valuation methods that can enable social and non-monetary valuation of ecosystems in low-income settings that reflect social norms and cultural value systems. The paper concludes with a discussion of how alternative ecosystem valuation methodology can enable new pathways towards climate change adaptation and the improvement of living standards that would be particularly suitable for low-income settings where natural resources are vulnerable and financial resources scarce.

Key words: non-market valuation, ecosystem valuation, social value, low-income settings, climate change adaptation, non-monetary

\section{Introduction}

As a global community, we face a tremendous challenge: to adapt to climate change in a time where natural environments are degrading at an alarming rate and where the exact extent of these implications remains uncertain (Bell, Johnson and Hobday, 2011; Liu et al. 2010; Jacobs et al. 2016; Pecl et al. 2017). This challenge is particularly pronounced in South Pacific Island Countries (SPICs) where the effects of climate change are expected to be severe and where the financial resources for adapting to these changes are scarce (Gonzales et al. 2017; Moberg and Folke, 1999). An important aspect of ecosystem valuation is improving our understanding of the benefits that ecosystems provide to human societies (Arias-Arévaloa et al. 2017; Costanza 
et al. 1997; Kenter et al. 2015; Pascual et al. 2010; de Groot et al. 2012). Local ecosystem valuation serves as an important insight into how local communities value their surrounding ecosystems, which can inform policy decisions and help design ecosystem and adaptation programs based on people's willingness-to-pay (WTP). Given the scarcity of financial resources in many of the SPICs, the WTP in monetary terms for preservation and adaptation programs is likely to be low, despite high reliance on ecosystems for sustaining livelihoods in most communities. However, individuals in these communities may be able to express their WTP in other units of wealth, e.g. time, food, etc. That is, the total incomes received through the direct use of natural resources may be high even though the monetary incomes are low. Alternative approaches to conducting ecosystem valuation are, therefore, especially important in the SPICs. Too often, the economic contribution of marine-based ecosystems is undervalued due to socio-economic and cultural aspects that differ substantially from Western societies, making it difficult to communicate the value of ecosystems in monetary terms (Gonzalez et al. 2017). First, monetary valuation mechanisms are often inappropriate for eliciting ecosystem value in the SPICs due to the low monetary income-levels. Second, decisions in the SPICs communities are commonly based on group discussions and local community well-being, rather than on individual benefits, which makes the individual utility approach unsuitable (Alam, 2006; Cvitanovic et al. 2016; Christie et al. 2012; Gonzalez et al. 2017; Kenter et al. 2011). Non-monetary valuation - and the social valuation - of ecosystems may offer a more inclusive approach for assessing and understanding the values that ecosystems provide for human well-being (Kenter et al. 2015). The 'social value of ecosystems' broadly refers to the non-use values that are commonly derived through a social or group setting, e.g. cultural, educational, religious, spiritual values of ecosystems (Christie et al. 2012; Bryan et al. 2011). Kenter et al. (2015) defines social values as the values or norms that are shared within a particular community or group of people, without specifically distinguishing social value from economic value. Although social values may also include monetary values in particular contexts (e.g. social WTP), Christie et al. 2012 and Bryan et al. 2011 maintain that the social value of ecosystems present a much broader 'umbrella' of values than economic values. Therefore, social value has previously been challenging to elicit, as it commonly requires non-monetary approaches with no specific units of measurement. These include (i) deliberative approaches, such as group-discussions or opinion polls; or (ii) analytical-deliberative approaches, such as participatory modelling, multi-criteria analysis, or deliberative (group) monetary valuation (Kenter et al. 2015). Alternative ecosystem valuation methodology may enable an identification of a broader set of climate change adaptation (CCA) 
strategies for communities that lack financial resources but possess tremendous natural capital along with incentives to act, e.g. for island countries that will be severely affected by climate change. Although a wealth of literature on the economic value of ecosystems has been produced a considerable gap remains in terms of supporting environmental decision-making and creating methods that are transparent, practical and feasible, and that lead to tangible environmental improvements (Olander et al. 2017; Kenter et al. 2015; Braat and de Groot, 2012). In addition, Van den Belt and Stevens (2016) conducted a qualitative discourse analysis of the most cited articles in the journal Ecosystem Services in the first four years of the journal, and identified the need for forming valuation methodology that incorporates the needs of lowincome societies and future generations as one of several research gaps in the ecosystem services literature.

In the context of the marine systems in the South Pacific, this paper proposes an expansion of ecosystem valuation methodology by means of combining non-monetary aspects of ecosystem values with the elicitation of the social value of ecosystems. The opportunities for expanding the mainstream valuation methodology from a monetary and individualistic focus to more inclusive means of assessing ecosystem values are tremendous. However, this paper specifically concentrates on the opportunities for eliciting ecosystem value in non-monetary terms in the SPICs, due to their low-income levels. In addition, this paper adopts a social focus on value elicitation, as opposed to the individual utility approach, due to the high compatibility with the cultural and social settings of many SPICs. While "integrated valuation allows for the ecological, socio-cultural and economic values of an ecosystem to be identified" (VillegasPalacio et al., 2016 p. 297), this review focuses exclusively on the non-monetary and social valuation of ecosystem services in relation to the value of ecosystems in the SPICs. Therefore, studies that explore other aspects of integrated valuation, e.g. monetary valuation and/or individual utility, have not been included as these are outside the scope of this review. The terms “integrated valuation” and “alternative valuation” are used inter-changeably throughout the paper, and refer to valuation methodology that integrates different aspects of ecosystem value through new and alternative means.

This paper applies recent theory on integrated valuation and shared values in the concrete context of SPICs, and argues that alternative valuation methods are needed to elicit relevant values and improve decision-making, i.e. the values of ecosystems to communities that are not (necessarily) market-based. A literature review on ecosystem valuation methodology is conducted which is intended to encourage the exploration of new and alternative ways of 
valuating ecosystems. The aim of eliciting alternative values of vulnerable ecosystems is twofold: (i) to enable a more inclusive elicitation of ecosystem values in low-income societies that reflect cultural values and social norms, and (ii) to explore the opportunities for forming CCA strategies, conservation programs and sustainability management based on the values and aspirations of communities with low or nil WTP. First, the paper reviews the various objectives of investigating the value of ecosystems in terms of their economic contribution, with specific focus on monetary value. Second, a discussion of the merits and shortcomings of the mainstream techniques in non-market valuation (NMV) methodology is discussed. Third, the paper evaluates the contemporary notion of value in economic analysis and contrasts its connotations to preceding notions of value. Fourth, the necessity of exploring alternative means to conducting ecosystem valuation in low-income settings is assessed and the future directions for exploring a new ecosystem valuation methodology explored. This is done by reviewing the studies that have employed alternative payment mechanisms to overcome the limitation of monetary valuation. It should be emphasized that this review is exemplary of the literature that exists on alternative payment- and integrated valuation tools, but is by no means exhaustive. That is, this review has been restricted to literature directly concerning methodologies that are estimated useful for the development of NMV approaches for low-income settings that are heavily reliant on their surrounding ecosystems, e.g. the SPICs. Fifth, a review of the SPICs' reliance on marine systems illustrates the compatibility of alternative ecosystem valuation methodology with the well-being and cultural context of low-income communities that will be severely affected by climate change. Lastly, it is demonstrated how non-monetary and socialvalue approaches to ecosystem valuation could open up new opportunities for adapting to climate change, improving human welfare and support policy and decision-making.

\section{Valuation of Natural Resources}

\subsection{Economic Valuation of Ecosystems}

Quantifying the economic value of ecosystems in monetary terms serves a plethora of purposes. In recent years, multiple research studies have attempted to quantify the monetary value of natural resources in several parts of the world (e.g. see Beaumont et al. 2008; Bennett and Birol, 2010; Biggs, 2011; Brander, Van Beukering and Cesar, 2007; Brunnschweiler, 2010; Costanza et al. 1997; Jones-Walters and Mulder, 2009; Laurans et al. 2013; Remoundou et al., 2009; Stoeckl et al. 2011; Turner et al. 2007). Even when the natural resources studied are considered 
non-market goods, changes in the level of their environmental quality will have an indirect effect on the value of other market goods, such as goods and services traded for tourism purposes (e.g., see Adamowicz et al. 1997; Alberini, Zanatta and Rosato, 2007; Alberini and Longo, 2006; Christie, Hanley and Hynes, 2007). The values that individuals assign to different types of natural resources have been explored in several research studies. Some of these aim at investigating the effect that a hypothetical change in one or more environmental attribute will generate on consumption and individual decision making (Adamowicz et al. 1997; Alberini, Zanatta and Rosato, 2007; Alberini and Longo, 2006; Christie, Hanley and Hynes, 2007; Dharmaratne and Brathwaite, 1998; Prayaga, Rolfe and Stoeckl, 2010; Remoundou et al. 2009). Other studies have explored the value of ecosystems with the objective of estimating the degree of "sustainability" in the human use of various ecosystems to enable a more efficient adaptation to climate change (Asafu-Adjaye, Brown and Straton, 2005; Jones, Hole and Zavaleta, 2012). Finally, Costanza et al. (1997) and Costanza et al. (2014) estimate the total value in monetary terms of the world's ecosystems, which has opened up a discussion about the magnitude of the contribution that specific biomes, such as coral reefs and mangroves, provide for societies on a global scale. Many of these biomes provide resources that underpin economic growth and development even though their ecosystem goods and services are not traded in markets.

Monetary valuation of ecosystems can provide valuable information in multiple ways. Economic valuation of ecosystem services in monetary terms, i.e. using market or pseudomarket prices to estimate socio-economic benefits, can help policy makers and institutions raise awareness among the public about the contribution that specific ecosystems make to human welfare (Ahmed et al. 2007; Bockstael et al. 2000; Costanza et al. 2014). Monetary valuation can provide public and private sectors with incentives to protect ecosystems, which in turn may help decrease poverty levels in developing countries (Christie et al. 2012). Monetary valuation is also beneficial in certain types of NMV techniques, e.g. where the objective is to investigate how a change in the state (or quality) of an ecosystem will affect tourism demand. For instance, if a coral reef degrades it is highly likely that tourism demand for trips to that coral reef will decline. The decline in tourism demand can exercise significantly negative impacts on the economy - especially if the country in question bases its income on tourism revenue (Kragt, Roebeling and Ruijs, 2009). Even if the objective of the economic valuation of ecosystems is more related to qualitative aspects of human welfare, monetary analysis can inform this valuation. 
Monetary figures can also be used to improve the understanding of how ecosystems provide benefits to human societies, even if these are of life-supporting and non-monetary character. A number of studies (e.g. see Brander, Van Beukering and Cesar, 2007; Laurans et al. 2013; Moberg and Folke, 1999; Stockl et al. 2011) explore the monetary value of the ecosystem services of coral reefs in different parts of the world. The aim of these monetary valuation studies is to facilitate a more efficient distribution of conservation resources. The monetary estimates of coral reefs' ecosystem services provide insights into how coral reefs contribute to human welfare in local coastal communities, and also to human welfare at larger scales. The large monetary estimates typically assigned to coral reefs’ ecosystem services (e.g. Costanza et al. 2017; 2014) illustrate in monetary terms the ecological importance of coral reefs' contribution to the functioning of adjoining ecosystems, such as mangroves and fresh-water environments. It may be particularly desirable to value and describe the benefits of these ecosystems in monetary terms when communicating their importance to a broader audience, as monetary figures are easily understood by the majority of people. As such, the objective of estimating the monetary values of specific ecosystems is not to create a "price-tag" of the world's ecosystems but to raise awareness about the universal importance of these to human societies (Costanza et al. 2014). Even if the monetary values assigned to the world's ecosystems are not accurate, they nonetheless initiate an urgent discussion about the extent to which particular ecosystems contribute to human welfare and the functioning of adjacent ecosystems.

\subsection{Methods in Non-Market Valuation (NMV)}

In order to address some of the challenges of valuing ecosystems in terms other than their market-based contribution, several techniques for NMV have emerged. NMV is the valuation of goods and services that are not directly defined by market prices, i.e. their value is formed through revealed preference methods or hypothetical markets (Baker \& Ruting, 2014; Robinson, 2001). What is commonly missing for most environmental goods and services is information about the value that individuals, or the community place on those goods and services, which can enable better decision-making in regards to environmental resource management (Robinson, 2001). For instance, people do not necessarily pay to go bush-walking in a national park, but nonetheless place value on its existence and environmental quality for their recreational benefit (Baker and Ruting, 2014). Therefore, several NMV techniques have 
emerged that estimate the monetary value that an individual place on goods and services that are not traded in the market.

First, the contingent valuation (CV) method can be used to estimate the economic value of a good or service that is not directly defined by market prices, e.g. the non-use or bequest value of an environmental resource (Dharmaratne \& Brathwaite, 1998; O’Garra, 2012; Prayaga, Rolfe \& Stoeckl, 2010). The CV method asks individuals to state their WTP to obtain particular goods and services, or their willingness-to-accept (WTA) monetary compensation to give up those goods and services (Applications of the contingent valuation method in developing countries, n.d.). Thus, a hypothetical market is created in which the monetary value for those goods and services can be elicited. For the NMV of environmental resources, the CV method is useful for estimating the bequest value of these (e.g. see Dharmaratne and Brathwaite, 1998; O’Garra, 2012; Prayaga, Rolfe and Stoeckl, 2010). The CV technique contributes to local policy-planning by providing useful information on incentive-based opportunities for preserving natural environments by outlining how much individuals would be willing to pay for different aspects of environmental attributes. Nonetheless, the CV method fails to investigate how hypothetical changes in the quality of a good might affect the future demand of that good. This may be of greater relevance for developing countries whose economy is driven by a tourism industry based on vulnerable natural resources, such as coral reefs and rain forests.

Second, the contingent behaviour (CB) technique makes it possible to estimate the income effect of a future hypothetical change in the quality of a natural resource. This is done by comparing respondents' willingness to visit a natural environment at its current environmental quality with the individuals' willingness to return to the same natural environment in a hypothetical scenario where one or more environmental attribute changes (e.g. studies by Alberini, Zanatta and Rosato, 2007; Alberini and Longo, 2006; Bennett and Birol, 2010; Christie, Hanley and Hynes, 2007; Dharmaratne and Brathwaite, 1998; Kragt, Roebeling and Ruijs, 2009; Prayaga, Rolfe and Stoeckl, 2010; Wattage et al. 2011; Wielgus et al. 2003). The CB technique is particularly relevant at more local scales, where the economy is based on revenue from tourism. Studies, such as those of Alberini, Zanatta and Rosato (2007), Bhat (2003) Dharmaratne and Brathwaite (1998), Kragt, Roebeling and Ruijs (2009), Prayaga, Rolfe and Stoeckl (2010), and Wielgus et al. (2003), have applied the CB technique to demonstrate the economic contribution of coral reefs and marine-based tourism activities to the local economy. These studies find that individuals' willingness to return to the environmental sites 
are considerably higher in scenarios with higher environmental quality, and vice versa thereby emphasising a strong economic rationale for preserving the sites and improving their environmental quality.

Third, the choice experiment technique (CE) - like the CB and the CV techniques - aims at investigating individual preferences for different types of goods, services or environmental settings. Nevertheless, it differs from the other techniques as it presents the respondent with a choice set of hypothetical options (Bennett and Birol, 2010). CE studies typically aim at gauging individuals' preferences for specific environmental attributes through the trade-offs they face when picking their preferred option (Alpizar, Carlsson and Martinsson, 2003).

Behavioural economic studies investigating the extent to which healthy natural environments contribute to the local economy, e.g. through tourism revenue, may provide useful information for policy makers. At more local scales, NMV studies positively contribute to the knowledge of how specific ecosystems goods and services support local economies by assessing the value of those environmental attributes. The results of NMV studies also inform policy makers about the opportunities for funding conservation programs through the public's aggregate WTP for these initiatives (see e.g. Ressurreição et al. 2011; Jobstvogt et al. 2014; Aanesen et al. 2015). Nonetheless, NMV studies are subject to respondents' individual budget constraints (Farley, 2012) as these commonly include a monetary component, i.e. a payment-vehicle. That is, money are used to define and convey values related to markets, or to estimate the marginal value of the trade-offs that individuals face in the choice between two goods. NMV studies of vulnerable ecosystem services in low-income settings are therefore likely to be biased as a monetary valuation may grossly underestimate the value of the ecosystems to the community (Christie et al. 2012; Saarikoski et al., 2016). In particular, NMV studies that explore the willingness of coastal communities to commit resources to combat climate change (or simply improve the environmental management of their natural resources) will fail to identify the magnitude of this willingness if the exploration is limited to a monetary analysis. Eliciting the non-monetary and social values of ecosystems may provide a stronger basis for action in many of the low-income SPICs. In fact, "utility" and "value” are concepts with different meanings and associations. In recent behavioural economic studies, it appears that they have somehow merged into one concept - a monetary utility trade-off. Following and developing the existing alternative discourse is urgently needed to better elicit the complex set of values that ecosystems provide. The monetary valuation approach based on individual utility needs to be expanded to investigate alternative value-aspects of ecosystems vulnerable to climate change, 
e.g. non-monetary aspects such as time, labour, geographical distance and overall social value. Although there are sound ethical and conceptual reasons for why more diverse valuation approaches are needed, there is also an important practical reason: diverse valuation approaches can contribute to actual problem solving and increase effectiveness.

\section{Theory and Concepts}

\subsection{The Theory of Ideas and the Concept of Value}

The concept of value first emerged with the thoughts of the Greek philosopher Plato during the fourth and third century B.C. Plato introduced the Theory of Ideas, in which he defined value as infinite and absolute; independent of human perception and material goods (Ueda, 2009 p. 682). Plato outlined the incompatibility of individual perception and knowledge by arguing that individual perception of the value of an object is irrelevant for the absolute, or actual, value of that object (Cherniss, 1936 pp. 450-451; Ueda 2009 p. 682). Plato maintained that only by applying knowledge, rather than investigating opinions, could the real value of an object begin to be understood: "Knowledge is not to be found in the perceptions but in the reflection upon them, since only in this process is it possible to grasp reality and meaning" (Cherniss, 1936 p. 451). According to Plato's theory of ideas, it is crucial to distinguish between knowledge and opinion. Knowledge (defined as pure thought and reason) relates to reality, whereas opinion (defined as belief and illusion) relates to individuals' ideas about future human existence (Plato, p. 266). In other words, to comprehend the meaning of value it is necessary to differentiate between notions of value, based on illusions and beliefs, and known value, based on thought and reason.

During the subsequent 2,400 years after Plato defined value through his Theory of Ideas, the concept of value continued to evolve in the fields of philosophy, economics and psychology. Particularly in economics, the concept of value became an individual concept applicable to the analysis of behavioural economic problems. The theory of marginal utility was introduced by Menger, Jevons and Walras in 1870. Marginal utility assesses value in terms of its use-value, i.e. the marginal value of a good is determined by how much satisfaction an individual associates with consuming one additional unit (Dobb, 1973). Von Neumann and Morgenstern (1972) expanded on the theory of marginal utility and integrated the concept of expected utility, essentially incorporating individual perception of uncertainty into the theory. According to the theory of expected utility, value is subject to an individual's perceptions of probability and 
uncertainty in relation to future events, especially when the individual faces a situation with considerable risks (Von Neumann and Morgenstern, 1972). The theoretical elements of both marginal utility and expected utility have been applied to multiple economic problems relating to individual behaviour and decision-making. These theories make it possible to analyse the rationales behind individual decision making in the context of consumerism and use-value the foundations on which welfare economic theory is built.

Although most studies on ecosystem valuation commonly assume that the concept of monetary valuation of ecosystems emerged in 1997 (e.g. with Costanza et al. 1997, among others), this is actually untrue. As Baveye, Baveye and Gowdy (2013) point out, the "monetization” of ecosystems was merely mainstreamed in 1997 "as an ideal strategy to get market economies to pay attention to the environment” (p. 233). Accordingly, the mainstream discourse of ecosystem valuation, which is predominantly focused on the monetary valuation of ecosystem services, emerged around 1997 (Baveye, Baveye and Gowdy, 2013). In addition, the approach to conducting monetary valuation has largely been based on the individual utility approach. In turn, the individual utility approach is based on various theories on economic value, i.e. the earlier discussed theories on marginal utility and expected utility. Particularly for policy and decision-making on environmental resources, the combination of the individual utility approach and the monetization of ecosystem services is restrictive, as it fails to address the complex diversity of many of the environmental problems that policy attempts to resolve. Ecosystem valuation "needs to be conducted at relevant policy scales that acknowledge the context and temporal dependent nature of ecosystem processes and human values... it is essential that the socio-cultural milieu that pervades and informs value articulating institutions are recognized by those individuals involved in economic assessments” (Hejnowicz and Rudd, 2017 p. 28). Valuation tools that move beyond individual utility and monetization are urgently needed to provide insights into ecosystems’ multitude of values.

\subsection{Rationale behind Individual Utility}

According to neoclassical economic theory, individual utility can be used to measure the value of a good or service (Ahlheim et al. 2010; Christie et al. 2012; Wegner and Pascual, 2011). It is assumed that an individual will make the choices they believe will maximize their utility (or consumer surplus) the most in order to provide them with the highest (or most) possible benefits. An individual's consumer surplus can be maximized to the extent that their time and 
financial budget permits it (Haener, Boxall and Adamowicz, 2001; Kragt, Roebeling and Ruijs, 2009). The individual utility function is useful for analysing the effect of changes in a market, e.g. how a change in the price, attributes of a good, or consumer preferences affects consumer demand. It is assumed that an individual is able to assign a monetary value to the good or services in question. As such, the principles that underpin the individual utility function form a valuation analysis that (i) investigates value on an individual level of perception, (ii) estimates only the monetary value of a good or service, and (iii) is restricted to goods or services that can be traded in the market. Given that the good or service is exchanged for monetary value, the valuation analysis is based solely on the individuals who are willing (and able) to pay for these (Ahlheim et al. 2010; Wegner and Pascual, 2011).

In other words, the theory of individual utility falls short of providing tools for valuation that (i) investigates value on a group- or social level, (ii) seeks to investigate non-monetary and qualitative aspects of goods or services, and (iii) concerns non-market goods i.e. goods that are not traded in the market (Fish, Church and Winter, 2016; Kenter et al., 2011; Wegner and Pascual, 2011). Despite these shortcomings, the individual utility function is commonly applied in the analysis of NMV results. Utilitarian assumptions may be particularly incompatible for the analysis of non-market goods, such as the benefits and values that ecosystems bring to societies. Christie et al. (2012 p. 75) states that "in Least Developed Countries, many people have low incomes, rely heavily on biodiversity to support subsistence livelihoods and may have limited experience of market mechanisms”. Therefore, the preferences of individuals with higher income is automatically given a higher priority than the preferences of individuals with low, or no, income (Ahlheim et al. 2010; Alam, 2006; Stoeckl. 2011, p. 128). As such, there is limited rationale for applying neoclassical economic theory or individual utility measures to a context classified as low-income or non-market based. This is particularly the case when attempting to understanding how ecosystems goods and services provide value to indigenous people and low-income settings, or in societies which operate by deliberative consensus (Christie et al. 2012; Kenter et al. 2011). Valuing environmental benefits by means of individual WTP dismisses the desires of subsistence communities' willingness to preserve their natural environments, as these may not be able to pay monetary values, but may assign high life-supporting, social and cultural values to their natural environments. 


\section{Alternative valuation of ecosystems is necessary}

People in developing or subsistence societies usually possess sound knowledge of how ecosystems are important for their well-being, but they may not possess sufficient financial resources to change the quality of their surrounding ecosystems (Kenter et al. 2011). It may be time to re-assess our perception of what "value" refers to, and explore how value can be assessed through different lenses (Jacobs et al. 2016) in order to facilitate more efficient CCA, and improve human welfare for societies at larger scales.

\subsection{Previous exploration of alternative ecosystem valuation methodology}

A few studies have employed alternative payment mechanisms to overcome the limitation of defining value in monetary terms. The following review has given particular attention to two special issues on shared values of ecosystem and integrated valuation methods from the journal Ecosystem Services ${ }^{1}$. "Integrated valuation allows for the ecological, socio-cultural and economic values of an ecosystem to be identified” (Villegas-Palacio et al., 2016 p. 297), However, this review focuses exclusively on the non-monetary and social valuation of ecosystem services for the specific purpose of forming more efficient CCA strategies and environmental resource management programs in low-income societies. The valuation methodology adopted in previous literature has predominantly been shaped by monetary valuation and individual decision-making. This is why social value of ecosystem services has been challenging to elicit, which is exactly why new types of valuation approaches are needed. Social and non-monetary aspects are relevant for the SPICs because "integrated valuation explicitly aims at including the multiple values and worldviews in a coherent and operational framework aiming at societal rather than (only) academic impact” (Jacobs et al. 2016 p. 214). Some studies investigate individuals' WTP together with their willingness to contribute time or labour (e.g. see Ahlheim et al. 2010; Alam, 2006; and Hung, Loomis and Thinh, 2007). The aim of these studies is to explore if there is a statistically and economically significant difference between valuing environmental change in terms of contributing monetary payments or time in low-income settings where financial resources are scarce. O’Garra (2009) estimates the bequest values of marine resources in fishing villages in Fiji through two payment vehicles: a monetary contribution (WTP) and time-based contributions (WtCT). Interestingly, O'Garra (2009) concludes that the opportunity cost of the time that locals in the fishing villages are

\footnotetext{
${ }^{1}$ Volume 21 and 22, respectively, 2016
} 
willing to contribute is almost three times the monetary value ${ }^{2}$ of their willingness to contribute money. Casey, Kahn and Rivas (2008) conduct surveys in indigenous and subsistence communities along the Amazon River to elicit the amount of compensation needed to compensate for potential ecosystem damage from oil spills in and around the Amazon River. Two alternative payment vehicles are adopted in which one is the improvement in different aspects of public goods (e.g. education or health care) and the other one is the delivery of free fuel. The alternative valuation mechanism manages to properly reflect the changes in wellbeing that the indigenous communities associate with changes in their natural environments. The study by Villegas-Palacio et al. (2016) incorporates ecological and socio-cultural dimensions of ecosystem value in order to design more targeted policies. Although their study places a heavy emphasis on exploring the perceptions of individuals, an individual WTPmeasure is incorporated in their methodology to be able to quantify the ecosystem's values. Villegas-Palacio et al. (2016) finds that where individuals' WTP is nil due to low income, these individuals express a dedicated willingness to contribute labour, or to modify their own environmental behaviours in order to protect and sustain their surrounding ecosystem's resources. Despite these findings, their potential to advance ecosystem valuation methodology further by means of exploring willingness to contribute labour (or change behaviour) in other settings are not discussed in further detail in the paper. The paper does, however, emphasize the need for forming a new valuation framework that manage to combine economic valuation methods with socio-cultural dimensions of ecosystem value.

De Valck (2015) applies the CE technique to investigate the relationship between geographical distance to a natural site and respondents' willingness to visit the natural site in the Province of Antwerp, Belgium. In the empirical analysis, the geographical distance is converted into a monetary figure by means of the travel cost method. Nevertheless, no monetary figure is presented to the respondents in the CE choice set. The study thereby gauges respondents' sensitivity to geographical distance when visiting natural sites and investigates the substitutability between environmental attributes and the distance to each natural site, rather than respondents' WTP. Wam et al. (2016) conduct an alternative valuation of the trade-offs between ecosystem services used for competing purposes (e.g. wood, game hunting and livestock grazing). Their study manages to evaluate the opportunity costs of sacrificing one purpose of ecosystem service-use relative to another by combining monetary and non-monetary

\footnotetext{
${ }^{2}$ In the empirical analysis, O’Garra (2009) converts the amount of time respondents are willing to commit into monetary figures according to the wage rate of time
} 
valuation methods. Saarikoski et al. (2016) presents the Multi-Criteria Decision Analysis (MCDA) approach which can be adapted to incorporate a deliberation process. This allows participants to reflect upon the causality patterns of different courses of environmental action, and discuss with one another which outcome is the most desirable for all participants concerned. Saarikoski et al. (2016) argue that the MCDA approach should incorporate a social WTP, but fails to identify the social willingness-to-commit (WTCommit) approach eliciting non-monetary resources, such as time, labour or a change in behaviour. The social WTCommit approach will be explained and discussed shortly. The objective of many of these discussed studies is to quantify the trade-offs related to specific decision-making scenarios, i.e. monetized marginal values related to environmental change. Hence, the objective of forming nonmonetary and socially optimal strategies is typically disregarded. Hansjürgens et al. (2016) emphasize the importance of eliciting social values in environmental valuation, but argue that the social value is - to some degree - already presented in public economic decision-making as the (social) common interest overrules that of individual interests. While there is truth to this point, the study does not elaborate further on opportunities for expanding environmental valuation methodology into more non-monetary aspects of social value.

Other studies discuss the need for assessing the values of ecosystem services in contexts other than monetary, such as cultural, social, shared, ecological or life-supporting (e.g. see Baveye, 2014; Chan, Satterfield and Goldstein, 2012; Baveye, Baveye and Gowdy, 2013; Fish, Church and Winter, 2016; de Souza Queiroz et al., 2017; Bryce et al., 2016; Irvine et al., 2016; and Jax et al. 2013). These studies acknowledge that some of the ecosystem values assessed may be quantified in monetary terms but emphasise that some values may be better communicated when described in qualitative terms, or put into the appropriate socio-cultural context. An important aspect of ecosystem valuation which individual utility, and individual WTP, fails to address is the well-being of the society. Although the results of an individual WTP study can be aggregated into a "social" measure of WTP, such aggregation rarely corresponds to the diverse dimensions of well-being in the society, such as cultural values and social settings. A more comprehensive and robust elicitation of the social - or shared - value of ecosystem services may necessitate discussion and reflection in group-settings rather than simply aggregating individual value (Kenter et al. 2011; Kenter et al. 2016a).

Social value has previously been challenging to gauge in NMV studies. Therefore, the valuation methodology adopted in the previous literature is predominantly shaped by the individual utility function. However, three major drawbacks characterise the monetary 
valuation of ecosystems in low-income and indigenous societies. These are (i) limited financial resources resulting in low (or nil) WTP for the environmental good or service, (ii) unfamiliarity with monetary payment systems resulting in biased results and/or inability to assign the environmental good or service a value that adequately reflects its perceived value, and (iii) the emphasis on decision making made at a group/social level, resulting in individual utility results that are obscure, or of lesser relevance for the societal context (Casey et al. 2008; Christie et al. 2012; Kenter et al. 2011). Alternative survey instruments that make it possible to identify and assess the role of cultural and social value systems may help address the challenges associated with the unfamiliarity of monetary payment systems, which characterise many indigenous and subsistence communities.

\subsection{Future research directions in ecosystem valuation}

Table 1 below shows the possible methodological combinations of individual and group-based ecosystem valuation approaches, respectively, with either monetary or non-monetary components. Several of the terms outlined in this table have been outlined in previous literature. As such, the terms are not meant to be exclusive to this particular paper, but illustrative of the need for future research directions. The most commonly adopted combination of techniques in ecosystem valuation is that of individual utility with a monetary element, e.g. individual WTP. However, a monetary component can also be included in group-based interviews (or surveys) in order to elicit the social WTP; that is, a community's willingness to contribute monetary resources for a change in ecosystem services (e.g. in the studies by Kenter et al. 2011; Petheram et al. 2010; and Saarikoski et al. 2016). On the right side of the table, non-monetary approaches to valuating ecosystems are listed. These can be individual- as well as a group-based. When the willingness of an individual to commit non-monetary resources such as individual time, additional travel distance, labour, etc. is explored this refers to individual WTCommit. As previously discussed, a few studies have explored individual WTCommit, e.g. the nonmonetary NMV studies of ecosystems in low-income settings (see Ahlheim et al. 2010; Alam, 2006; and Hung, Loomis and Thinh, 2007; O’Garra, 2009; and Villegas-Palacio et al. 2016) or the individual WTA non-monetary compensation for various items, instead of monetary payment (see Casey, Kahn \& Rivas, 2008; Wam et al. 2016). Moreover, De Valck (2015) explored individual WTCommit travel distance in the high-income setting of Belgium. The aforementioned studies are based on individual utility but may offer some new insights into individuals’ WTCommit resources, or accept non-monetary compensation. Finally, group- 
based interviews or surveys may be based entirely on non-monetary trade-offs (such as a community's WTCommit time, travel further distances, or commit to monitoring environmental thresholds, etc.). This combination of non-monetary valuation with a groupbased survey setting is referred to as social WTCommit as it assesses the willingness of a society to commit resources other than money for a change in ecosystem services.

Although a few studies (e.g. Saarikoski et al. 2016; and Villegas-Palacio et al. 2016) mention the opportunity for forming a Social WTP approach, no social WTCommit study was identified in this review paper. Nonetheless, the social WTCommit technique would be particularly suitable for the SPICs due to the deliberative consensus of many of their societies coupled with low-income levels. Note that both the social WTP and the social WTCommit techniques may identify feasible means of actions for CCA and socio-economic progress not previously identified by the individual utility approach. Specifically for the social WTCommit, this approach could identify which means of action and resources the community is willing to commit to, if monetary resources are inadequate or undesirable. Deliberation is an optional tool for both social WTP and social WTCommit, and may provide respondents with the possibility to discuss in depth the causes and consequences of changes in their surrounding ecosystems, which may alter the results of the social WTP and social WTCommit studies, respectively. Previous research in the field of integrated ecosystem valuation has largely focused on how to elicit new aspects of ecosystem values, such as cultural, shared or social values. Forming new tools to eliciting ecosystem values is not only about integrating methods - it is also about revising the current operating space of the monetary methods. A substantial research gap remains in terms of utilising this new valuation knowledge to form tangible, feasible and efficient strategies for creating better environmental resource management, improving living standards for low-income societies and for addressing climate change. In other words, there is an urgent need to address how a new framework for forming ecosystem valuation approaches can be integrated into policy and decision-making to enable actions and create outcomes (Kenter et al. 2015; Braat and de Groot, 2012; Olander et al. 2017). The valuation approach social WTCommit - presented in this paper offers a possibility for forming more comprehensive ecosystem valuation and for utilising those valuation results to form feasible and efficient strategies for environmental resource management. It may also present a new framework for improving living standards, although this is subject to further research. The relevance and importance of exploring the social WTCommit approach in the SPICs is discussed next. 


\section{[Insert table 1 here]}

\section{The alternative valuation of ecosystems in the SPICs}

Although there are multiple contexts in which alternative value elicitation could improve knowledge acquisition and contribute to environmental decision-making (Braat and de Groot, 2012; Kenter et al. 2015), this section will outline why the social WTCommit approach is especially suitable for the SPICs given their heavy reliance on ecosystems resources, limited financial resources and vulnerability to climate change.

\subsection{Reliance on marine resources in the SPICS}

The economic contribution of many marine-based ecosystems in the South Pacific is often underestimated. This is due to economic activities that are resource-based and take place outside of formal markets as opposed to market-based activities that involve monetary payments (Fish, Church and Winter, 2016). Moreover, the economic contribution of marinebased ecosystems has proven difficult to estimate through the commonly adopted individual utility approach. Customary resource tenure arrangements are in place in many South Pacific Islands that do not reflect individual utility-decisions or market-based mechanisms (Gonzales et al. 2017). Social and cultural aspects clearly need to be identified in order to avoid spending time and resources implementing strategies that are incompatible with cultural value systems. O’Garra (2009) finds that pursuing financial (or material) wealth in Fijian societies is regarded as morally unacceptable, making strategies that have financial profit as their main objective irrelevant for Fijian communities. A case study assessing the economic, social and environmental efficiency of engineering-based adaptation relative to ecosystem-based adaptation in the Lami Town of Fiji concludes that engineering solutions will incur financial costs five times as high as ecosystem-based adaptation (Rao et al. 2013). To enable a more accurate assessment of the economic value of marine ecosystems in the SPICs, a more holistic approach that takes into account social arrangements and cultural norms is needed. Also, the channels through which goods and services of economic value are exchanged need to be considered and incorporated in the valuation approach. Insights like these highlight the 
importance of understanding the social value constellations of a society prior to forming environmental management or CCA programs.

\subsection{Reliance on coral reef ecosystems}

An important aspect of the ecosystem valuation of marine ecosystems is raising awareness about the benefits that the ecosystems provide to human societies, e.g. the way in which coral reef-ecosystems support and sustain human life in coastal communities. In turn, a local ecosystem valuation of coral reefs can serve as an important tool in formulating new policies related to the environmental resource management of coral reefs (Gonzales et al. 2017). Many coastal communities in the SPICs derive substantial values from coral reefs but may not possess the financial resources to pay for improvements in their environmental quality that is usually required in environmental management programs. Coastal communities in the SPICs are likely to assign high social values to improvements in coral reefs' ecosystems due to the ability for coral reefs to generate significant benefits for their well-being.

Most of the SPICs are heavily reliant on coral reefs' ecosystems goods and services for food security, poverty reduction, coastal protection and for the ecosystem functioning of adjoining ecosystems (Brander, Van Beukering and Cesar, 2007; Cesar, 2000 p. 15; Hoegh-Guldberg et al., 2011; Moberg and Folke, 1999). Coral reefs may become damaged through coral bleaching, through reduced resilience and capacity to maintain their structural complexity, and through direct damage caused by severe storms or cyclones - all of which are considered to be direct impacts of global climate change (Bell, Johnson and Hobday, 2011). The benefits from improving the local environmental management of coral reefs may be enormous and farreaching, given the tremendous economic, cultural, recreational and ecological value that coral reefs provide to human societies (Reid et al. 2012). The human benefits of better coral reefs management are likely to be particularly significant for the coastal communities in the SPICs. In contrast, the degradation of coral reefs will have severe and long-lasting negative impacts, e.g. through diminished food security, decreasing local incomes, lower living standards, higher vulnerability to climate change, and declining economic growth due to tourists alternating their vacation choice to countries with healthy coral reefs (Moberg and Folke, 1999). Effective environmental management of coral reefs in the SPICs is therefore crucial for enabling longterm and sustainable CCA of the islands. For those reasons, a new ecosystem valuation 
methodology capable of eliciting and communicating the social value of coral reefs to South Pacific Island-communities is urgently needed.

\subsection{Cultural Context and Community engagement}

Communication and understanding are important albeit commonly under-assessed aspects of forming successful environmental management and CCA strategies in coastal communities vulnerable to climate change. In particular, the role that culture and social values play in the engagement of communities have hitherto been either overlooked or poorly understood in the SPICs. Cvitanovic et al. (2016) investigate the relationship between the effectiveness of CCA science and food security in a number of Pacific Island communities, concluding that the integration of local communities is the foundation for the successful implementation of CCA strategies. A lack of understanding in Samoan communities about the potential impacts of climate change on sectors vital to economic development, such as tourism, is one of the main barriers to proactively adapting to climate change (Wong et al. 2013). Other studies find that the main challenge to facilitating successful ecosystem preservation and CCA in the SPICs is unlikely to be financial resources, but more likely to be community engagement, collective action and government capacity (Daigneault, Brown and Gawith, 2016; Hills et al. 2013). Previous research in Kiribati has indicated that small-island nations are open to the formation of new conservation and environmental management arrangements of their marine ecosystems due to their heavy reliance on the resources that these provide to their societies (Watson, Claar and Baum, 2016). In an assessment of 42 coral reef fisheries in developing countries, Cinner et al. (2012) concluded that the engagement of communities was vital for the successful management of fisheries and coral reefs resources. Collective action of the communities was found to be a key ingredient in enabling sustainable resource management.

Insights into the cultural value systems of subsistence communities in different locations are fundamental for building CCA strategies as these can identify obstacles and opportunities for future progress. A better understanding of the relationship between human societies and coastal environments in subsistence communities could further help shape new environmental management and adaptation strategies. Exploring the human-environment relationship inevitably requires the social value of the natural environment for the community in question to be explored (Robinson, James and Whitehead, 2016). The difficulty of communicating the social value of vulnerable ecosystems to low-income coastal communities in monetary terms 
highlights the importance of developing new ecosystem valuation techniques. In low-income coastal communities, the greatest force for changes to resource management will often be the willingness of the community to collectively drive the changes, based on their social and cultural aspects (Fisher et al., 2014; Watson, Claar and Baum, 2016), rather than individual or social WTP. Therefore, a social WTCommit valuation approach may enable a more comprehensive understanding of what "value" entails in different cultural, economic and social settings (Fish, Church and Winter, 2016; Farley, 2012). A better understanding of the social value of important local ecosystems may enable CCA strategies to better reflect cultural value systems, thereby facilitating more effective CCA strategies of marine systems vulnerable to climate change in the South Pacific - and lastly, an increase in overall human well-being.

\subsection{Deliberation in Social Value Elicitation}

The social value of ecosystems typically needs to be discussed and reflected upon in groups in order to be identified, which makes deliberation a fundamental part of social value-elicitation. For ecosystem valuation, the relationship between the environmental good (or service) and the well-being of the respondents need to be established through deliberation prior to assigning the environmental good any value (Irvine et al., 2016). In turn, the collective value of the ecosystem $^{3}$ will emerge as a result of the lessons drawn from knowledge exchange and deliberation in the group discussions (Kenter et al. 2011; Wegner and Pascual, 2011). The elicitation of social values through deliberation may contribute considerably to our knowledge of how ecosystems underpin life in low-income coastal communities that are at risk of being severely affected by climate change (Kenter et al. 2011). In turn, the acquisition of social valueknowledge may offer specific non-monetary strategies for mitigating climate change effects by integrating the desires of local communities. As Kenter et al. (2015, p. 87) notes, "a more social approach to valuation has the potential to provide a more convincing and legitimate evidence base [translating into tangible improvements in terms of environmental outcomes]".

Kenter et al. (2011) employ the CE method in the Solomon Islands in which the CE surveys are conducted as group discussions - "social surveys" - with subsistence communities, thereby eliciting the collective (social) value of the Solomon Island-respondents' surrounding natural environments. Kenter et al. (2011) include a deliberation approach as part of conducting the CE. After the initial presentation of choice sets, two intervention exercises are conducted in

\footnotetext{
${ }^{3}$ or environmental good/service
} 
which respondents are asked to (i) quantify the value of a range of household items, and to (ii) identify and discuss five negative impacts of two crops grown in their society through deliberation. The deliberation exercise allows the respondents to discuss and reflect upon the relationships between socioeconomic changes and environmental degradation. As a result, respondents assign ecosystem services much higher monetary values than prior to the deliberation exercise, revealing a higher social value of ecosystems to their society. Similar studies by Orchard-Webb et al. (2016) and Kenter (2016) integrate deliberation into their valuation of ecosystem services in England and Scotland, respectively. Although there are elements of social (or 'shared') value elicitation in both studies, the results are mainly presented and contrasted in monetary terms, through WTP measures. Petheram et al. (2010) integrates deliberation into their interviews with indigenous people in the Arnhem Land of Australia. In this context, deliberation leads respondents to conclude that socioeconomic issues, such as poverty and health are of greater concern for their indigenous communities than climate change-related issues. Finally, Ranger et al. (2016) incorporate deliberation into decisionmaking processes relating to the design of Marine Protected Areas to improve participation and engagement of stakeholders.

Deliberation is a suitable social value-survey tool (Irvine et al., 2016), regardless of whether the survey includes a monetary component or not. “Ostrom (2000) suggests a significant proportion of respondents follow social norms when considering collective good situations... In terms of the payment vehicle the norms of reciprocity, trust and fairness are likely to be relevant... Payment vehicle choice needs to reflect shared norms of trust and fairness" (in Powe, 2007, p. 29). The findings of these studies emphasize the importance of making both deliberation and group survey methodology integral parts of conducting surveys in subsistenceor indigenous settings, particularly for exploring the value systems on which societies are formed. Farber, Costanza and Wilson (2002) point to the potential of deliberation to overcome the limitations of the individual utility function commonly adopted in ecosystem valuation, emphasizing the ability of deliberation to elicit collective value and to do so through a more democratic valuation process. That way, the social value emerging because of the dialogue and reflection amongst respondents is automatically given a higher importance than individual value, based on respondents' pre-held assumptions. Deliberation may be especially important for value elicitation in subsistence communities where socio-economic issues, such as famine or drought, often take precedence over environmental issues (Christie et al. 2012). Deliberation 
can work as an educational and awareness-increasing tool in making respondents realize amongst themselves - the magnitude of the benefits that ecosystems provide for their societies.

\section{Discussion}

\subsection{Understanding the Values of Ecosystems}

The problem with utility when it is applied in economic terms is that it limits the analysis to one that solely focuses on the benefits, or "profitability", of a resource in monetary terms. Few NMV studies have focused exclusively on more qualitative aspects of value, development and prosperity in relation to the value of natural environments. A NMV technique including a monetary component will inevitably presume that natural environments are only worth in dollars what individuals (i) are willing to pay for them, or (ii) believe natural environments are worth - the former aspects concerns individual desire along with ability to pay (Ahlheim et al. 2010), and the latter aspects concerns individual opinion. This is a contradictory approach, as it neglects precisely the multitude of non-monetary values that ecosystems provide to human welfare that cannot be traded in the market (Stoeckl et al. 2011). In the event that individuals assign low monetary values to ecosystem services through a utility-based WTP, such results will communicate to the broader public that the ecosystem's goods and services are of low value, indicating that the incentives to preserve and restore its environmental quality are limited.

A concept of value has emerged that correlates the degree of value with a degree of perceived individual utility. Therefore, the importance (value) that the public associates with ecosystem value is shaped by how (much) individuals believe these ecosystems contribute to the utilitarian aspects of their individual lives. Ueda et al. (2009) maintain that the contemporary concept of value often generates contradictory predicaments in decision-making as the perceived values of individuals rarely correspond with the more holistic values of the society in which the individuals reside. Most people are aware that many natural environments are depleting at an alarming rate; that the climate is changing at a rapid pace; and that these changes are likely to affect the lives of many people on the planet. However, the assumption that there is a linear relationship between monetary values and the ecosystems goods and services of, e.g. coral reefs is profoundly flawed (Farber, Costanza and Wilson, 2002; Braat and de Groot, 2012; Farley, 
2012; Fish, Church and Winter, 2016). For instance, the more degraded a coral reef becomes the more limited is its ability to sustain its own ecosystem and those of its adjoining ecosystems. The economic contribution of many marine-based ecosystems in the South Pacific tends to be grossly underestimated (Gonzalez et al. 2017; Fish, Church and Winter, 2016). The need for forming valuation methodology that incorporates the needs of low-income societies presents a critical research gap in the literature of ecosystem services (van den Belt and Stevens, 2016). In addition to this, valuation methodology that can facilitate and support actionable and practical environmental improvements presents another critical gap in policy and decisionmaking (Olander et al. 2017; Kenter et al. 2015; Braat and de Groot, 2012). A new framework for eliciting the values of ecosystem services may not only provide insights into how the these ecosystems support economies and human well-being - it may also facilitate a more comprehensive understanding of the concept of "value" in settings that differ in cultural, geographical and social terms. In most of the low-income coastal communities in the SPICs, the greatest driver for change in the direction of poverty reduction and environmental conservation will be the willingness of the community to take action (Fisher et al. 2014; Watson, Claar and Baum, 2016). Cultural and social aspects like these make it critical to adopt a new framework for identifying, eliciting and understanding the values that ecosystem services provide to communities. Therefore, this paper proposes the application (and testing) of a new framework for eliciting the Social WTCommit in future ecosystem valuation studies in order to elicit new aspects of ecosystem values. More importantly, this can help to identify opportunities and obstacles for driving social, economic and environmental changes - which are urgently needed in the SPICs.

\subsection{Consequences of Maintaining Monetary Valuation of Ecosystem Resources}

If the objective behind the application of ecosystem valuation methodology is to minimize information gaps and create incentives to protect the ecosystems of the planet, we may be missing the ultimate focal point. Alternative - or integrated - valuation methods that enable a more holistic and "absolute” value of ecosystems to be elicited could be particularly important in low-income settings with limited purchasing power, where the application of monetarydriven techniques may provide obscure or irrelevant results (Christie et al. 2012). The current turn of the discourse may be leading us further away from identifying means of adapting to climate change and to creating incentives for furthering human development. The monetary 
approach to forming ecosystem valuation methodology can be useful in specific developed contexts. However, the opportunities to explore the multiple non-monetary values of nature to people in low-income societies are limited as the current suite of NMV techniques hinders such exploration. NMV techniques seek to elicit estimates of the value that individuals derive from ecosystems. Nonetheless, many of these "values” may be of non-monetary character in settings where communities derive substantial life-supporting values from natural environments but are unable to value these in monetary terms.

The reviewed papers from the special issues on shared values of ecosystem and integrated valuation methods from the journal Ecosystem Services ${ }^{4}$ present new ideas and reflections on the theoretical and methodological developments needed to better understand ecosystem values. One of the themes in the special issues is "methodological innovation in deliberative and non-monetary valuation methods” (Kenter, 2016b, p. 180). Although social WTP is mentioned as a necessary future research methodology, no mention is given of a social WTCommit framework. This may indeed be because social value remains difficult to elicit. However, it may also be because it has not (yet) been possible to form a non-monetary valuation method capable of supporting the development of tangible and actionable strategies for environmental improvements. The reflections of the included papers from the special issues on shared values and integrated valuation methods only emphasize the need for methodological frameworks that can enable practical and feasible environmental outcomes.

The mainstream concept of NMV is based on what Plato would deem notions of value, based on belief and illusion, rather than actual knowledge. Interestingly, the latter necessitates a reflection upon the former. Thus, the limitations of the mainstream approach to conducting NMV could be overcome by incorporating "group-based deliberative processes that involve reflecting on and discussing values and information to form reasoned opinions” (Kenter et al., 2016a, p. 359). By exploring the social value of ecosystems through deliberation in the SPICs, reasoned knowledge about ecosystems and potential CCA strategies may emerge, enabling the known value of their vulnerable ecosystems to be elicited rather than a notion of their value. Likewise, exploring non-monetary means of forming CCA strategies and improving living standards (such as the willingness to commit time, labour or community resources) may pave a hitherto unknown road towards the long-term sustainability of marine resources and improved living standards. The social WTCommit approach introduced in this paper is a new

\footnotetext{
${ }^{4}$ Volume 21 and 22, respectively, 2016
} 
framework for conducting ecosystem valuation. It may offer a practical pathway towards more comprehensive ecosystem valuation along with tangible strategies to improve ecosystems through the collective actions of communities. Eliciting the social value of ecosystems through deliberation may also improve the awareness among communities about CCA issues, along with obstacles and opportunities for future progress (Irvine et al., 2016). A social WTCommit approach may better integrate the desires and social value constellations of low-income communities into CCA and environmental management programs. Thus, the social WTCommit approach is highly likely to lead to better outcomes for environmental resource management together with improved living standards, though this is subject to further research. Turning the mainstream discourse in a new direction may help identify new and more sustainable strategies for adapting to climate change and for furthering human development.

\section{Conclusion}

The discourse on the economic values of ecosystems originated with a desire to minimise information gaps in academia and public policy. Globally, climate change will continue to impact upon human lives. Information on how to adapt to climate change is urgently needed. The mainstream discourse on ecosystems valuation presumes that quantitative data on the economic value of ecosystems and biomes is the primary means of identifying solutions to climate change. This is an unfortunate direction as it may be leading us further away from the heart of the matter: to generate prosperity and improving human well-being by means of forming actionable environmental management strategies. Currently, this mainstream discourse approach is being contested based on theory and experiences from ecosystem service valuations in various real life contexts. In the context of the SPICs, this paper proposes expanding the mainstream framework of ecosystem valuation to combine non-monetary valuation with social/group-based survey methods. The ecosystem valuation framework of a non-monetary social WTCommit approach could help elicit the underestimated values of ecosystems in low-income settings, and do so through a more democratic process of deliberation that incorporates the interests of the society as a whole. Although social valuation may consist of monetary elements, a non-monetary valuation of ecosystems in the SPICs may identify if there are non-monetary resources in the communities with vulnerable ecosystems that may represent a stronger basis for action towards CCA and sustainable human development, than CCA and environmental management programs based on monetary resources. 
The mainstream approach to conducting - and forming - ecosystem valuation techniques is built upon the assumption that a linear relationship exists between monetary values and natural environments. The commonly adopted approach to ecosystem valuation reflects a reality in which capitalistic aspects of value are deemed to be of primary importance, thus disregarding the multitude of benefits that ecosystems provide for human lives. As a result, the opportunities for forming CCA strategies are restricted by the magnitude of their perceived financial contribution, and by individual budget constraints. Therefore, it is critically important to continue developing the mainstream discourse in the direction of alternative ("integrated") valuation approaches that enable deeper understandings of the complex set of values that ecosystems provide. Specifically for the SPICs, non-monetary and social approaches to ecosystem valuation can make it possible to gain a more comprehensive understanding of how ecosystems support human life in these low-income communities. In turn, this may identify new pathways towards building coastal communities more resilient to climate change. Finally, the social WTCommit framework presented in this paper could also facilitate actionable strategies for improving human welfare in vulnerable small-island societies. The combination of non-monetary valuation with group-based survey settings and deliberation will explore the reality and meaning of ecosystem values in the SPICs, rather than the commonly held beliefs and illusions about their ecosystems’ economic value. 


\section{Reference list}

Aanesen, M., Armstrong, C., Czajkowski, M., Falk-Petersen, J., Hanley, N. and Navrud, S. (2015). Willingness to pay for unfamiliar public goods: Preserving cold-water coral in Norway. Ecological Economics, 112, pp. 53-67.

Adamowicz, W., Swait, J., Boxall, P., Louviere, J. and Williams, M. (1997). Perceptions versus objective measures of environmental quality in combined revealed and stated preference models of environmental valuation. Journal of Environmental Economics and Management, 32(1), pp. 65-84.

Ahlheim, M., Frör, O., Heinke, A., Duc, N. M. and Dinh, P. V. (2010). Labour as a utility measure in contingent valuation studies: how good is it really? (No. 13-2010). FZID discussion papers.

Ahmed, M., Umali, G. M., Chong, C. K., Rull, M. F. and Garcia, M. C. (2007). Valuing recreational and conservation benefits of coral reefs - the case of Bolinao, Philippines. Ocean \& Coastal Management, 50(1), pp. 103-118.

Alam, K. (2006). Valuing the environment in developing countries: problems and potentials. Asia Pacific Journal on Environment and Development, 13(1), pp. 27-44.

Alberini, A., Zanatta, V. and Rosato, P. (2007). Combining actual and contingent behaviour to estimate the value of sports fishing in the Lagoon of Venice. Ecological Economics, 61(2), pp. 530-541.

Alberini, A. and Longo, A. (2006). Combining the travel cost and contingent behaviour methods to value cultural heritage sites: evidence from Armenia. Journal of Cultural Economics, 30(4), pp. 287-304.

Alpizar, F., Carlsson, F. and Martinsson, P. (2003). Using choice experiments for non-market valuation. Economic Issues - Stoke On Trent, 8(1), pp. 83-110.

Applications of the contingent valuation method in developing countries. (n.d.). FAO corporate document repository. Retrieved from http://www.fao.org/docrep/003/x8955e/x8955e03.htm (18 Oct 2017)

Arias-Arévaloa, P., Gómez-Baggethunb, E., Martín-Lópezd, B., \& Pérez-Rincóne, M. (2017). Widening the evaluative space for ecosystem services: A taxonomy of plural values and valuation methods. Forthcoming in Environmental Values. 
Asafu-Adjaye, J., Brown, R. and Straton, A. (2005). On measuring wealth: a case study on the state of Queensland. Journal of Environmental Management, 75(2), pp. 145-155.

Baker, R. and Ruting, B. (2014). Environmental policy analysis: a guide to non-market valuation. Australian Government Productivity Commission. January 2014. Retrieved from http://www.pc.gov.au/research/supporting/non-market-valuation/non-market-valuation.pdf (accessed 8 Jan 2017)

Baveye, P. C. (2014). Perspectives from the field: ecological economic perspective in environmental practice: much-needed common sense amid overwhelming market rhetoric. Environmental Practice, 16(03), pp. 246-248.

Baveye, P. C., Baveye, J. and Gowdy, J. (2013). Monetary valuation of ecosystem services: it matters to get the timeline right. Ecological Economics, 95, pp. 231-235.

Beaumont, N. J., Austen, M. C., Mangi, S. C. and Townsend, M. (2008). Economic valuation for the conservation of marine biodiversity. Marine Pollution Bulletin, 56(3), pp. 386-396. Bell, J. D., Johnson, J. E. and Hobday, A. J. (Eds.). (2011). Vulnerability of tropical Pacific fisheries and aquaculture to climate change. SPC FAME Digital Library. Noumea: Secretariat of the Pacific Community.

Bennett, J. and Birol, E. (Eds.). (2010). Choice Experiments in Developing Countries: Implementation and Policy Implications. Cheltenham, UK: Edward Elgar Bhat, M. G. (2003). Application of non-market valuation to the Florida Keys marine reserve management. Journal of Environmental Management, 67(4), pp. 315-325.

Biggs, D. (2011). Understanding resilience in a vulnerable industry: the case of reef tourism in Australia. Ecology and Society, 16(1).

Bockstael, N. E., Freeman, A. M., Kopp, R. J., Portney, P. R. and Smith, V. K. (2000). On measuring economic values for nature. Environmental Science \& Technology, 34(8), pp. 1384-1389.

Braat, L. C., \& de Groot, R. (2012). The ecosystem services agenda: bridging the worlds of natural science and economics, conservation and development, and public and private policy. Ecosystem Services, 1(1), 4-15.

Brander, L. M., Van Beukering, P. and Cesar, H. S. (2007). The recreational value of coral reefs: a meta-analysis. Ecological Economics, 63(1), pp. 209-218. 
Brunnschweiler, J. M. (2010). The Shark Reef Marine Reserve: a marine tourism project in Fiji involving local communities. Journal of Sustainable Tourism, 18(1), pp. 29-42.

Bryan, B. A., Raymond, C., Crossman, N. D., \& King, D. (2011). Comparing spatially explicit ecological and social values for natural areas to identify effective conservation strategies. Conservation Biology, 25(1), 172-181.

Bryce, R., Irvine, K. N., Church, A., Fish, R., Ranger, S., \& Kenter, J. O. (2016). Subjective well-being indicators for large-scale assessment of cultural ecosystem services. Ecosystem Services, 21, 258-269.

Casey, J. F., Kahn, J. R. and Rivas, A. A. (2008). Willingness to accept compensation for the environmental risks of oil transport on the Amazon: A choice modeling experiment. Ecological Economics, 67(4), pp. 552-559.

Cesar, H. S. J. (Ed.). (2000). Collected Essays on the Economics of Coral Reefs. Kalmar, Sweden: CORDIO

Chan, K. M., Satterfield, T. and Goldstein, J. (2012). Rethinking ecosystem services to better address and navigate cultural values. Ecological Economics, 74, pp. 8-18.

Cherniss, H. (1936). The philosophical economy of the theory of ideas. American Journal of Philology, pp. 445-456.

Christie, M., Fazey, I., Cooper, R., Hyde, T. and Kenter, J. O. (2012). An evaluation of monetary and non-monetary techniques for assessing the importance of biodiversity and ecosystem services to people in countries with developing economies. Ecological Economics, 83, pp. 67-78.

Christie, M., Hanley, N. and Hynes, S. (2007). Valuing enhancements to forest recreation using choice experiment and contingent behaviour methods. Journal of Forest Economics, 13(2), pp. 75-102.

Cinner, J. E., McClanahan, T. R., MacNeil, M. A., Graham, N. A., Daw, T. M., Mukminin, A., ... and Campbell, S. J. (2012). Comanagement of coral reef social-ecological systems. Proceedings of the National Academy of Sciences, 109(14), pp. 5219-5222.

Costanza, R., de Groot, R., Sutton, P., van der Ploeg, S., Anderson, S. J., Kubiszewski, I., ... and Turner, R. K. (2014). Changes in the global value of ecosystem services. Global Environmental Change, 26, pp. 152-158. 
Costanza, R., d'Arge, R., De Groot, R., Farber, S., Grasso, M., Hannon, B., ... and Van Den Belt, M. (1997). The value of the world's ecosystem services and natural capital. Nature, 387, pp. 253-260.

Cvitanovic, C., Crimp, S., Fleming, A., Bell, J., Howden, M., Hobday, A. J., ... and Cunningham, R. (2016). Linking adaptation science to action to build food secure Pacific Island communities. Climate Risk Management, 11, pp. 53-62.

Daigneault, A., Brown, P., \& Gawith, D. (2016). Dredging versus hedging: comparing hard infrastructure to ecosystem-based adaptation to flooding. Ecological Economics, 122, pp. 2535.

De Groot, R., Brander, L., Van Der Ploeg, S., Costanza, R., Bernard, F., Braat, L., ... \& Hussain, S. (2012). Global estimates of the value of ecosystems and their services in monetary units. Ecosystem services, 1(1), 50-61.

de Souza Queiroz, L., Rossi, S., Calvet-Mir, L., Ruiz-Mallén, I., García-Betorz, S., SalvàPrat, J., \& de Andrade Meireles, A. J. (2017). Neglected ecosystem services: Highlighting the socio-cultural perception of mangroves in decision-making processes. Ecosystem Services, 26, 137-145.

De Valck, J. (2015). Valuation and mapping of cultural ecosystem services. PhD. Arenberg Doctoral School. Leuven, Belgium

Dharmaratne, G. S. and Brathwaite, A. E. (1998). Economic valuation of the coastline for tourism in Barbados. Journal of Travel Research, 37(2), pp. 138-144.

Dobb, M. (1973). Theories of Value and Distribution Since Adam Smith. Cambridge: Cambridge University Press.

Farber, S. C., Costanza, R. and Wilson, M. A. (2002). Economic and ecological concepts for valuing ecosystem services. Ecological Economics, 41(3), pp. 375-392.

Farley, J. (2012). Ecosystem services: The economics debate. Ecosystem Services, 1(1), 40 49.

Fish, R., Church, A., \& Winter, M. (2016). Conceptualising cultural ecosystem services: a novel framework for research and critical engagement. Ecosystem Services, 21, 208-217. 
Fisher, J. A., Patenaude, G., Giri, K., Lewis, K., Meir, P., Pinho, P., ... \& Williams, M. (2014). Understanding the relationships between ecosystem services and poverty alleviation: a conceptual framework. Ecosystem Services, 7, 34-45.

Gonzales, R., Ram-Bidesi, V., Pascal, N., Brander, L., Fernandes, L., Salcone, J. \& Seidl, A. (2017). Economic assessment and valuation of marine ecosystem services: Fiji. A publication to the MACBIO project. SPREP/IUCN/GIZ, Suva, Fiji. 102 pp.

Haener, M. K., Boxall, P. C. and Adamowicz, W. L. (2001). Modeling recreation site choice: do hypothetical choices reflect actual behaviour? American Journal of Agricultural Economics, 83(3), pp. 629-642.

Hansjürgens, B., Schröter-Schlaack, C., Berghöfer, A., \& Lienhoop, N. (2017). Justifying social values of nature: economic reasoning beyond self-interested preferences. Ecosystem Services, 23, 9-17.

Hejnowicz, A. P., \& Rudd, M. A. (2017). The Value Landscape in Ecosystem Services: Value, Value Wherefore Art Thou Value?. Sustainability, 9(5), 850.

Hills, T., Carruthers, T. J. B., Chape, S. and Donohoe, P. (2013). A social and ecological imperative for ecosystem-based adaptation to climate change in the Pacific Islands. Sustainability Science, 8(3), pp. 455-467.

Hoegh-Guldberg, O., Andréfouët, S., Fabricius, K. E., Diaz-Pulido, G., Lough, J. M., Marshall, P. A. and Pratchett, M. S. (2011). Vulnerability of coral reefs in the tropical Pacific to climate change. In: Bell, J. D., Johnson, J. E. and Hobday, A. J. (Eds.), Vulnerability of Tropical Pacific Fisheries and Aquaculture to Climate Change (pp. 251-296). Noumea: Secretariat of the Pacific Community.

Hung, L. T., Loomis, J. B. and Thinh, V. T. (2007). Comparing money and labour payment in contingent valuation: the case of forest fire prevention in Vietnamese context. Journal of International Development, 19(2), pp. 173-185.

Irvine, K. N., O’Brien, L., Ravenscroft, N., Cooper, N., Everard, M., Fazey, I., ... \& Kenter, J. O. (2016). Ecosystem services and the idea of shared values. Ecosystem Services, 21, 184193.

Jacobs, S., Dendoncker, N., Martín-López, B., Barton, D. N., Gomez-Baggethun, E., Boeraeve, F., ... \& Pipart, N. (2016). A new valuation school: Integrating diverse values of nature in resource and land use decisions. Ecosystem Services, 22, 213-220. 
Jax, K., Barton, D. N., Chan, K. M., de Groot, R., Doyle, U., Eser, U., ... and Haines-Young, R. (2013). Ecosystem services and ethics. Ecological Economics, 93, pp. 260-268.

Jobstvogt, N., Hanley, N., Hynes, S., Kenter, J. and Witte, U. (2014). Twenty thousand sterling under the sea: estimating the value of protecting deep-sea biodiversity. Ecological Economics, 97, pp. 10-19.

Jones, H. P., Hole, D. G. and Zavaleta, E. S. (2012). Harnessing nature to help people adapt to climate change. Nature Climate Change, 2(7), pp. 504-509.

Jones-Walters, L. and Mulder, I. (2009). Valuing nature: the economics of biodiversity. Journal for Nature Conservation, 17(4), pp. 245-247.

Kenter, J. O., Bryce, R., Christie, M., Cooper, N., Hockley, N., Irvine, K. N., ... \& Raymond, C. M. (2016). Shared values and deliberative valuation: Future directions. Ecosystem Services, 21, 358-371.

Kenter, J. O. (2016a). Integrating deliberative monetary valuation, systems modelling and participatory mapping to assess shared values of ecosystem services. Ecosystem Services, 21, 291-307.

Kenter, J. O. (2016b). Editorial: Shared, plural and cultural values. Ecosystem Services, 21, 175-183.

Kenter, J. O., O'Brien, L., Hockley, N., Ravenscroft, N., Fazey, I., Irvine, K. N., ... and Church, A. (2015). What are shared and social values of ecosystems?. Ecological Economics, 111, pp. 86-99.

Kenter, J. O., Hyde, T., Christie, M. and Fazey, I. (2011). The importance of deliberation in valuing ecosystem services in developing countries_-evidence from the Solomon Islands. Global Environmental Change, 21(2), pp. 505-521.

Kragt, M. E., Roebeling, P. C. and Ruijs, A. (2009). Effects of Great Barrier Reef degradation on recreational reef-trip demand: a contingent behaviour approach. The Australian Journal of Agricultural and Resource Economics, 53(2), pp. 213-229.

Laurans, Y., Pascal, N., Binet, T., Brander, L., Clua, E., David, G., ... and Seidl, A. (2013). Economic valuation of ecosystem services from coral reefs in the South Pacific: taking stock of recent experience. Journal of Environmental Management, 116, pp. 135-144. 
Liu, S., Costanza, R., Farber, S. \& Troy, A. (2010). Valuing ecosystem services - theory, practice, and the need for a transdisciplinary synthesis. Annals of the New York Academy of Sciences, 1185, 54-78

Moberg, F. and Folke, C. (1999). Ecological goods and services of coral reef ecosystems. Ecological Economics, 29(2), pp. 215-233.

O’Garra, T. (2012). Economic valuation of a traditional fishing ground on the coral coast in Fiji. Ocean \& Coastal Management, 56, pp. 44-55.

O’Garra, T. (2009). Bequest values for marine resources: how important for indigenous communities in less-developed economies?. Environmental and Resource Economics, 44(2), pp. 179-202.

Olander, L., Polasky, S., Kagan, J. S., Johnston, R. J., Wainger, L., Saah, D., ... \& Yoskowitz, D. (2017). So you want your research to be relevant? Building the bridge between ecosystem services research and practice. Ecosystem Services, 26, 170-182.

Orchard-Webb, J., Kenter, J. O., Bryce, R., \& Church, A. (2016). Deliberative democratic monetary valuation to implement the ecosystem approach. Ecosystem Services, 21, 308-318.

Pascual, U., Muradian, R., Brander, L., Gómez-Baggethun, E., Martín-López, B., Verma, M., ... \& Farley, J. (2010). The economics of valuing ecosystem services and biodiversity. TEEBEcological and Economic Foundation.

Pecl, G. T., Araújo, M. B., Bell, J. D., Blanchard, J., Bonebrake, T. C., Chen, I. C., ... \& Falconi, L. (2017). Biodiversity redistribution under climate change: Impacts on ecosystems and human well-being. Science, 355(6332), eaai9214.

Petheram, L., Zander, K. K., Campbell, B. M., High, C. and Stacey, N. (2010). 'Strange changes': Indigenous perspectives of climate change and adaptation in NE Arnhem Land (Australia). Global Environmental Change, 20(4), pp. 681-692.

Plato, H.D.P. Lee, and M. S. Lane (2007). The Republic (D. Lee, Trans.) New York, NY: Penguin Group

Powe, N. A. (2007). Redesigning Environmental Valuation: Mixing Methods within Stated Preference Techniques. Edward Elgar Publishing. 
Prayaga, P., Rolfe, J. and Stoeckl, N. (2010). The value of recreational fishing in the Great Barrier Reef, Australia: a pooled revealed preference and contingent behaviour model. Marine Policy, 34(2), pp. 244-251.

Rao, N. S., Carruthers, T. J. B., Anderson, P., Sivo, L., Saxby, T., Durbin, T., Jungblut, V., Hills, T. and Chape, S. (2013). An economic analysis of ecosystem-based adaptation and engineering options for climate change adaptation in Lami Town, Republic of the Fiji Islands. A technical report by the Secretariat of the Pacific Regional Environment Programme. Apia, Samoa: SREP 2013.

Ranger, S., Kenter, J. O., Bryce, R., Cumming, G., Dapling, T., Lawes, E., \& Richardson, P. B. (2016). Forming shared values in conservation management: an interpretive-deliberativedemocratic approach to including community voices. Ecosystem Services, 21, 344-357.

Reid, C., Marshall, J., Logan, D. and Kleine, D. (2012). Coral Reefs and Climate Change: The Guide for Education and Awareness $2^{\text {nd }}$ edition. Brisbane: CoralWatch, The University of Queensland.

Remoundou, K., Koundouri, P., Kontogianni, A., Nunes, P. A. and Skourtos, M. (2009). Valuation of natural marine ecosystems: an economic perspective. Environmental Science \& Policy, 12(7), pp. 1040-1051.

Ressurreição, A., Gibbons, J., Dentinho, T. P., Kaiser, M., Santos, R. S., and Edwards-Jones, G. (2011). Economic valuation of species loss in the open sea. Ecological Economics, 70(4), pp. 729-739.

Robinson, C. J., James, G. and Whitehead, P. J. (2016). Negotiating Indigenous benefits from payment for ecosystem service (PES) schemes. Global Environmental Change, 38, pp. 21-29.

Robinson, J. (2001). A Review of techniques to value environmental resources in coastal zones. Milestone Report. CRC for Coastal Zone Estuary and Waterway Management, University of Queensland. Australia: Indooroopilly

Saarikoski, H., Mustajoki, J., Barton, D. N., Geneletti, D., Langemeyer, J., GomezBaggethun, E., ... \& Santos, R. (2016). Multi-criteria decision analysis and cost-benefit analysis: Comparing alternative frameworks for integrated valuation of ecosystem services. Ecosystem Services, 22, 238-249. 
Stoeckl, N., Hicks, C. C., Mills, M., Fabricius, K., Esparon, M., Kroon, F., ... and Costanza, R. (2011). The economic value of ecosystem services in the Great Barrier Reef: our state of knowledge. Annals of the New York Academy of Sciences, 1219(1), pp. 113-133.

Turner, R. A., Cakacaka, A., Graham, N. A. J., Polunin, N. V. C., Pratchett, M. S., Stead, S. M. and Wilson, S. K. (2007). Declining reliance on marine resources in remote South Pacific societies: ecological versus socio-economic drivers. Coral Reefs, 26(4), pp. 997-1008.

Ueda, K., Takenaka, T., Váncza, J., \& Monostori, L. (2009). Value creation and decisionmaking in sustainable society. CIRP Annals-Manufacturing Technology, 58(2), pp. 681-700.

van den Belt, M., \& Stevens, S. M. (2016). Transformative agenda, or lost in the translation? A review of top-cited articles in the first four years of Ecosystem Services. Ecosystem Services, 22, 60-72.

Villegas-Palacio, C., Berrouet, L., López, C., Ruiz, A., \& Upegui, A. (2016). Lessons from the integrated valuation of ecosystem services in a developing country: Three case studies on ecological, socio-cultural and economic valuation. Ecosystem Services, 22, 297-308.

Von Neumann, J. and Morgenstern, O. (1972). Theory of Games and Economic Behaviour $2^{\text {nd }}$ edition. Princeton University Press.

Wam, H. K., Bunnefeld, N., Clarke, N., \& Hofstad, O. (2016). Conflicting interests of ecosystem services: multi-criteria modelling and indirect evaluation of trade-offs between monetary and non-monetary measures. Ecosystem Services, 22, 280-288.

Watson, M. S., Claar, D. C. and Baum, J. K. (2016). Subsistence in isolation: Fishing dependence and perceptions of change on Kiritimati, the world's largest atoll. Ocean \& Coastal Management, 123, pp. 1-8.

Wattage, P., Glenn, H., Mardle, S., Van Rensburg, T., Grehan, A. and Foley, N. (2011). Economic value of conserving deep-sea corals in Irish waters: a choice experiment study on marine protected areas. Fisheries Research, 107(1), pp. 59-67.

Wegner, G. and Pascual, U. (2011). Cost-benefit analysis in the context of ecosystem services for human well-being: A multidisciplinary critique. Global Environmental Change, 21(2), pp. 492-504.

Wielgus, J., Chadwick-Furman, N. E., Zeitouni, N. and Shechter, M. (2003). Effects of coral reef attribute damage on recreational welfare. Marine Resource Economics, 18(3), pp. 225238. 
Wong, E., Jiang, M., Klint, L., DeLacy, T., Harrison, D. and Dominey-Howes, D. (2013).

Policy environment for the tourism sector's adaptation to climate change in the South PacificThe case of Samoa. Asia Pacific Journal of Tourism Research, 18(1-2), pp. 52-71. 